\title{
Sara Prades Plaza, España y su historia. La generación de 1948. Castelló de la Plana: Publicacions de la Universitat Jaume I, 2014, 392 págs.
}

Esta monografía de Sara Prades Plaza, investigadora y profesora en la Universitat Jaume I, es una importante contribución al conocimiento de la historia y la historiografía durante la época del franquismo en España. Su autora centra su análisis en una época muy concreta de la dictadura de Franco, poco más de una década entre mediados de los años cuarenta y mediados de los cincuenta del siglo veinte. En esa primera etapa de definición y consolidación del régimen dictatorial, la doctora Prades Plaza distingue la producción cultural, sobre todo historiográfica, de un grupo de intelectuales con una clara vocación por establecer las bases ideológicas de la dictadura y determinar el rumbo de la política española. A ese grupo se le conoce como "grupo de Arbor", "grupo del Opus Dei” o, como se denomina en el ensayo que reseñamos, "generación de 1948”. Esta se compone, fundamentalmente, de jóvenes historiadores y filósofos universitarios. Rafael Calvo Serer, catedrático de Historia Universal Moderna y Contemporánea en la Universidad de Valencia, es su líder indiscutible, aunque también sobresalen personalidades como Florentino Pérez Embid o Vicente Rodríguez Casado. El Centro Superior de Investigaciones Científicas (CSIC), el Ateneo de Madrid, la Universidad Internacional Menéndez Pelayo y la Escuela de Estudios Hispanoamericanos de la Rábida son las principales plataformas institucionales que este grupo controla y utiliza como soporte financiero y propagandístico. Sus principales medios de difusión son las revistas Arbor, del CSIC, y Ateneo, puesta en circulación por la institución que lleva su nombre, y los textos publicados en la colección $O$ crece o muere, también del Ateneo, o en la editorial Rialp fundada por miembros del Opus Dei, así como los seminarios y conferencias que tienen lugar regularmente en Madrid, Santander, Sevilla o Huelva.

Frente a la propuesta ideológica que proporcionaba el falangismo, puesto en entredicho tras la Segunda Guerra Mundial y la derrota del fascismo europeo, la generación de 1948 surge con la intención de ofrecer al régimen una visión distinta tanto del pasado como del futuro de España. Si la falange se asocia con un "antiliberalismo postliberal" (pág. 328), es decir una lucha contra el liberalismo a partir de un programa político moderno y totalitario, por su parte la generación de 1948, útil para la imagen externa del franquismo en el contexto de la Guerra Fría, niega el valor de la secularización y las revoluciones contemporáneas y además pretende encauzar el destino de España mediante un tradicionalismo propio del Antiguo régimen. En efecto, entre los elementos políticoculturales que este grupo defiende es pilar fundamental la monarquía conservadora que asuma el papel, ya secular, de defensora y difusora del catolicismo. Tanto es así que precisamente la insistencia explícita, por parte de Calvo Serer a comienzos de los años cincuenta, a la restauración monárquica propicia el comienzo de la desarticulación de este grupo de presión y de su capacidad para ejercer influencia en las esferas de poder.

Esos objetivos más o menos inmediatos se apoyan en un discurso histórico que, naturalmente, tiene a España como tema casi único de estudio. Se defiende un pasado nacional homogéneo, una historia que marginaliza los problemas y contradicciones y hace hincapié en la singularidad de un pueblo escogido para liderar la universitas cristiana. 
Anclada en los métodos y presupuestos de la historiografía positivista, la generación de 1948 se apropia del legado intelectual de Marcelino Menéndez Pelayo, aunque la figura del santanderino es también reclamada por otras facciones político-culturales de la misma época. La Historia Antigua pasa casi desapercibida para este grupo que tampoco presta mucha atención a la Historia Medieval, más que para reivindicar un regionalismo peninsular que no siempre encaja bien con su idea de unidad nacional. La Historia Moderna, sobre todo los tiempos de los Reyes Católicos, y todavía más la persona del rey Fernando, son los temas preferidos por estos ideólogos que ven en la Paz de Westfalia (1648) el inicio de una decadencia que no finaliza hasta la Guerra Civil, cuyo desenlace en 1939 da lugar a una nueva era gloriosa similar a la que había generado la toma de Granada en 1492.

Sara Prades Plaza ha hilado fino a la hora de desbrozar lo que en apariencia se nos presenta, en las primeras décadas del franquismo, como un conjunto bastante homogéneo de manifestaciones culturales que legitima la dictadura de Franco. Para ello analiza en profundidad una amplia serie de artículos y libros publicados en una estrecha franja temporal, así como la correspondencia epistolar y los archivos personales de buena parte de los protagonistas. El análisis se extiende a la relación que existe entre el programa de la generación de 1948 y aquellos otros proyectos europeos afines, particularmente el desarrollado por Action Française y el pensamiento de Charles Maurras. Sin duda, esa ha sido una tarea ardua que el lector puede apreciar bien por la similitud, y más aún pobreza intelectual, de la mayor parte de los argumentos estudiados. Pues al margen de las particularidades de su proyecto, lo que esta generación tiene para ofrecer, en términos intelectuales, no parece que sea merecedor de calificarse como innovador ni como alternativo. De hecho, en esas décadas centrales del siglo XX en España se observa un retroceso con respecto al dinamismo historiográfico de los años previos a la Guerra Civil, y no es hasta los años sesenta y setenta, a partir sobre todo del contacto con la historiografía francesa, que la historia que se practica en España cobra nuevos impulsos.

Signo de la calidad científica del trabajo que comentamos es que la doctora Prades Plaza haya optado por exponer los resultados de su investigación de una manera sincrónica. En efecto, en lugar de narrar el nacimiento, desarrollo y extinción de la generación de 1948 de una manera diacrónica, el libro ofrece una división por temas que consta de los siguientes apartados: el capítulo primero presenta la situación política e historiográfica de los primeros años del franquismo, en el segundo se define la composición de la generación de 1948, en el tercer y cuarto se analizan las características de su discurso historiográfico y de su programa político-cultural, y finalmente, en el capítulo quinto, se pone en relación la acción de este grupo con la de otras fuerzas políticas del mismo periodo.

La decisión de una redacción sincrónica ha sido un acierto dada la facilidad con la que se lee el texto y se aprehenden sus contenidos. Sin embargo, eso mismo repercute negativamente en lo redundante de algunas informaciones, como la propia autora parece reconocer (pág. 367), y también, añadiría yo, en un didacticismo excesivo. El apartado de las conclusiones, por ejemplo, es un claro y preciso resumen de todo lo desarrollado anteriormente en el libro, carente, no obstante, de interpretaciones. El lector agradece esa ordenación final de la información sobre la que ha venido reflexionando a lo largo del 
texto, aunque ya de por sí cada uno de los capítulos y apartados del libro contiene síntesis finales. Pero además, al llegar a las conclusiones, el lector espera ver los resultados que se han alcanzado mediante la investigación, nuevas perspectivas que no han sido antes planteadas.

Desgraciadamente, en mi opinión la autora se esconde demasiado detrás de lo que es sin duda un buen análisis. Se podría haber prescindido, por ejemplo, de numerosas citas textuales que, sobre todo en la parte central del libro, no ayudan a clarificar unos argumentos que ya de por sí son suficientemente claros, sino que contribuyen a hacer la lectura más monótona y a echar más en falta la lectura crítica, las interpretaciones originales de quien lleva a cabo la investigación.

Francisco Gómez Martos

Johns Hopkins University

fgomezm1@jhu.edu

Fecha de recepción: 8 de enero de 2016.

Fecha de aceptación: 23 de enero de 2016.

Publicación: 30 de junio de 2016.

Para citar este artículo: Francisco Gómez Martos, "Sara Prades Plaza, España y su historia. La generación de 1948. Castelló de la Plana: Publicacions de la Universitat Jaume I, 2014, 392 págs.”, Historiografías, 11 (enero-junio, 2016): pp. 145-147.

http://www.unizar.es/historiografias/historiografias/numeros/11/gomez.pdf 